\title{
Water Mixtures as Working Fluids in Organic Rankine Cycles ${ }^{\dagger}$
}

\author{
Costante Invernizzi $\left.{ }^{1, *} \mathbb{(}\right)$, Marco Binotti ${ }^{2}$, Paola Bombarda ${ }^{2}$, Gioele Di Marcoberardino ${ }^{1}$, \\ Paolo Iora ${ }^{1}$ and Giampaolo Manzolini ${ }^{2}$ (D) \\ 1 University of Brescia, Department of Mechanical and Industrial Engineering, via Branze 38, \\ 25123 Brescia, Italy \\ 2 Politecnico di Milano, Department of Energy, via Lambruschini 4, 20156 Milano, Italy \\ * Correspondence: costante.invernizzi@unibs.it; Tel.: +39-030-3715569 \\ $+\quad$ The original paper was presented in: Bombarda P., Di Marcoberardino G., Invernizzi C., Iora P. and \\ Manzolini G., Water mixtures as working fluids in organic Rankine cycles. In Proceedings of the Heat \\ Powered Cycles Conference 2018, Bayreuth, Germany, 16-19 September 2018; Riehl, R., Preißinger, M., \\ Eames, I., Tierney, M., Eds.; ISBN 978-0-9563329-6-7.
}

Received: 12 May 2019; Accepted: 4 July 2019; Published: 8 July 2019

check for updates

\begin{abstract}
This work explores the possibility to adopt in organic Rankine cycle (ORC) plants mixtures of water (acting as solvent) plus an organic compound (acting as solute) as the working fluid. Initially an evaluation of the thermodynamic properties of the mixtures is performed, in order to assess their properties, and to point out the molar fractions which entail a near-azeotropic behaviour. Four species from three different classes of chemical compounds are investigated: 2,2,2-trifluoroethanol and n-butanol for alcohols, where the first is fluorinated, acetonitrile for nitrile class and 2-methylpyrazine as a heterocyclic aromatic compound. Simultaneously, the thermal stability of the pure substances considered as the possible solute for the mixtures is experimentally investigated in order to estimate the temperature applicability range. The ORC plant performance, from a low-enthalpy geothermal heat source (hot water stream from 100 to $200{ }^{\circ} \mathrm{C}$ ), adopting the selected mixtures as the working fluid is finally evaluated, and the analysis includes a preliminary discussion on the turbine design; results are compared with respect to the reference case of a hypothetical plant adopting water as the working fluid.
\end{abstract}

Keywords: ORC; working fluids; water mixtures; near-azeotropic mixtures; thermal stability

\section{Introduction}

The choice of the right working fluid in an organic Rankine cycle (ORC) is a crucial issue [1-4]. An amazing number of papers in the open literature deals with this issue [5-9]: the question is still open because, on one side better performance is desired, and, on the other side, the working fluid must comply with the evolving environmental regulations. Though most of the papers related to this subject deal just with the cycle efficiency $[10,11]$, it is essential to also investigate other aspects such as component sizing (mainly turbine and heat exchangers design), safety and environmental compliance. Usually pure fluids are selected as the working fluid in ORC plants and are mainly refrigerants, hydrocarbons and poly-siloxanes $[7,12,13]$.

In addition to pure fluids as working fluids, many authors also considered the possibility to recourse to mixtures of many different fluids, mainly zeotropic mixtures, and several studies discuss performances of mixture of hydrocarbon, refrigerants, siloxanes and other common ORC working fluids [14-23]. The main advantage of using mixtures is their temperature glide in evaporation. Unfortunately, at the same time, a high temperature glide in condensation could penalize the 
thermodynamic cycles. Furthermore, some authors suggest the use of mixtures could improve off-design system performance, varying the mixture composition with continuity [24-26].

Water, the most used working fluid for large Rankine cycles, is a cheap and safe fluid (non-flammable and non-toxic) but it is not a suitable working fluid in Rankine cycles of (relatively) small power size or low temperature. The thermodynamic properties of steam, low molecular complexity and molar mass and high critical point, lead to large and expensive multistage turbines as well as to complex plant schemes (superheating section and feedwater heaters) and to liquid formation during the expansion. Water is, indeed, the choice working fluid for large-scale Rankine cycles operating with high temperature energy sources in a wide variety of efficient cycle configurations, from the saturated cycles of nuclear power stations to the coal fired ultra-supercritical cycles. The smallest steam turbines currently available have sizes around $10 \mathrm{MW}$ [27].

Mixtures of organic fluids and water can overcome the limitations of pure water as the working fluid with potential advantages in terms of safety (reduced flammability and toxicity) and of thermodynamic properties that can be tailored to the heat source power and temperature level.

This work deals with the adoption of a water-based mixture to overcome the limits of the use of pure water in ORC plants. Mixtures of water for possible application in ORCs have already been investigated in the past [28-30] and recently considered again [31]. There are many fluids miscible in water and forming near-azeotropes such as alcohols, acids, esters and others. The well-known ammonia/water mixture was studied for the Kalina cycle [28,32]: unfortunately, both water and ammonia have low molar mass and molecular complexity causing high temperature glides during isobaric evaporation/condensation, as shown in Figure 1, thus requiring rather complex plant configuration (i.e., heat exchangers design).

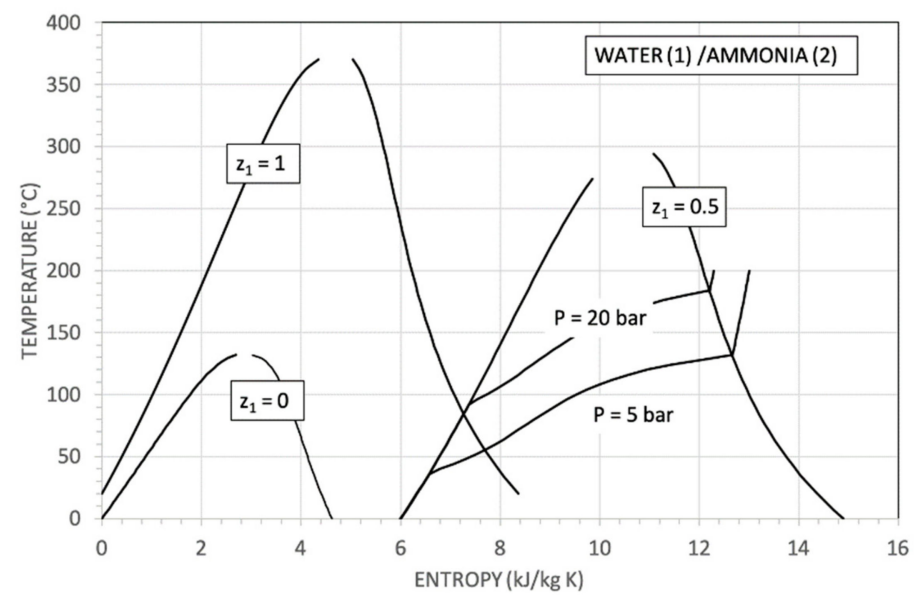

Figure 1. Saturation curves (bubble and dew lines) in temperature-entropy (T-S) plane for water/ammonia mixtures with different compositions. $\mathrm{z}_{1}=1$ and $\mathrm{z}_{1}=0$ correspond to pure water or pure ammonia respectively.

This work aimed to investigate the thermodynamic behaviour of two-component mixtures where water was mixed with a soluble species: the produced working fluid should, on one side, increase the molecular complexity and reduce the critical point with respect to pure water and, on the other side, reduce the flammability and the possible toxicity of the solute. The application of the mixture in an ORC that recovers heat from a geothermal source was considered as a case study. The thermodynamic properties of the different working fluid mixtures and of the thermodynamic cycle performance were evaluated with Aspen Plus ${ }^{\circledR}$ (v 9.0). Experimental tests on thermal stability of some selected fluids were conducted in order to define the applicability range. The final aim was to find a mixture composition (with water as the main component) that guaranteed good conversion efficiency together with a convenient turbine sizing and an almost dry expansion (vapour quality at the end of the expansion close to one). Heat exchangers design, requiring detailed transport properties, was not considered. 


\section{Water Mixtures Selection}

This work proposes the adoption of a water-based mixture in order to overcome the limits of the use of pure water in ORC plants: the addition of proper substances to water can result in an eligible working fluid. Among the species that are soluble in water, the screening was focused on fluids that can limit the main drawbacks of pure water in small scale applications, related to its low molecular complexity, low molar mass and high critical temperature. The adoption of zeotropic mixtures, as a working fluid, has been proposed and discussed [33,34], aiming at minimizing the heat introduction irreversibility in the frame of heat recovery applications; however, it should be also considered that, depending on the available coolant, the gain at the primary heat exchanger could vanish considering the irreversibility in the heat rejection process. For this reason, mixtures with the presence of an azeotropic point or near-azeotropic blends, within the typical ORC operating conditions (pressure (p), temperature $(\mathrm{T})$ ), were selected in order to minimize differences in compositions between the vapour phase and the liquid phase that entail temperature glide in the heat rejection system, as shown in Figure 1 for the water/ammonia mixture. Furthermore, the mixing with water (considered here as the solvent) reduced the flammability and the possible toxicity of the solute.

There are many fluids miscible in water and forming near-azeotropes, typically with four or fewer carbon atoms such as alcohols, acids, esters, ketones, aldehydes and others. Mixtures of water and alcohols have already been considered [35]. Only simpler alcohols are totally miscible with water, but, having a relatively low molar mass and molecular complexity, their mixing with water does not substantially reduce the main thermodynamic drawbacks of pure water.

Four species from three different classes of chemical compounds were investigated: 2,2,2-trifluoroethanol and n-butanol for alcohols, where the first is fluorinated, acetonitrile for nitrile class and 2-methylpyrazine as a heterocyclic aromatic compound. The water mixtures with 2,2,2-trifluoroethanol and with 2-methylpyrazine were already presented in previous works as promising working fluids for a waste heat recovery ORC application from diesel engines [36-41]. Recent studies stated that the water/alcohol mixtures are more stable with respect to the pure alcohol as the presence of water seems to repress their thermal decomposition [42]. In this paper, the criteria for the choice of the solute are introduced and discussed on a rational thermodynamic basis, with the hope of identifying the right component.

The thermodynamic properties of the pure species and water-based mixtures were evaluated with Aspen Properties ${ }^{\circledR}$ (v9.0) [43]. The NRTL activity coefficient model with the RKS equation of state for the evaluation of the vapour fugacity was adopted: this method is suitable for polar compounds, so highly non ideal mixtures, at low pressures (typically below 10 bar) [44,45]. The necessary binary interaction coefficients were regressed from NIST (National Institute of Standard and Technology) database experimental data within the software. The calculated VLE results were in good agreement with literature experimental values as reported for example in Figure 2 for the water/n-butanol mixture: experimental values (dots and crosses) of temperatures and liquid and vapour molar composition (at 1 bar) are reported against the calculated results (solid lines).

The main thermodynamic properties of the considered pure substances (critical temperature $T_{c r}$, critical pressure $\mathrm{p}_{\mathrm{cr}}$, molar mass $\mathrm{MM}$, molecular complexity parameter $\sigma$, normal boiling temperature $\mathrm{T}_{\mathrm{b}}$ ), are summarized in Table 1 . The parameter $\sigma$ is defined as the dimensionless slope of the vapour saturation curve in the temperature-entropy (T-S) plane for a reduced temperature of 0.7 [46]: $\sigma=\frac{\mathrm{T}_{\mathrm{cr}}}{\mathrm{R}}\left(\frac{\mathrm{dS}}{\mathrm{dT}}\right)_{\mathrm{T}_{\mathrm{r}}=0.7}$. All the selected fluids have a lower critical point and a higher molar mass with respect to the water. Moreover, Table 2 reports flash temperatures, flammability and the health hazard levels from the Nation Fire Protection Association (NFPA) 704 standard [47].

A typical isobaric VLE diagram of water base mixture is represented in Figure 2. Here the water(1)/n-butanol(2) mixture at atmospheric pressure was considered: the dew line and the bubble line are reported against the molar concentration of component 1 on abscissa. The two solid lines were calculated starting from the experimental data (dots and crosses in the chart). The bubble line represents the locus of temperatures at which the first bubble of fluid was formed while the dew point 
is determined by the formation of the first drop. The values of the dew temperature and the bubble temperature were the same at the two extremities (pure water or pure n-butanol), while in the rest of the VLE diagram the two temperatures were different and the gap between them represented the temperature glide during phase transition except for the azeotrope that was formed for a molar fraction of water equal to 0.75 . The chart can be divided into three zones: (i) above the dew line (zone V), the mixture was only vapour; (ii) between the dew and the bubble lines there was a vapour-liquid equilibrium (zone $\mathrm{L}+\mathrm{V}$ ) where the molar composition of the two phases was a function of the temperature (except for the azeotrope); (iii) below the bubble line (zone L), the mixture was just liquid. In particular, the water/n-butanol mixture presented an additional zone in the liquid phase, defined as " $\mathrm{L}_{1}+\mathrm{L}_{2}$ ", where the two fluids were not miscible. As the molar composition of this particular region was around the azeotropic point, the mixture was not further investigated as a potential working fluid.

Table 1. Main thermodynamic properties of the investigated working fluids.

\begin{tabular}{cccccc}
\hline Fluid & $\mathbf{T}_{\mathbf{c r}}\left({ }^{\circ} \mathbf{C}\right)$ & $\mathbf{p}_{\mathbf{c r}}(\mathbf{b a r})$ & $\mathbf{M M ~} \mathbf{( k g} / \mathbf{k m o l})$ & $\mathbf{\sigma}(-)$ & $\mathbf{T}_{\mathbf{b}}\left({ }^{\circ} \mathbf{C}\right)$ \\
\hline water & 373.95 & 220.64 & 18.02 & -10.38 & 100.00 \\
2,2,2-trifluoroethanol & 225.42 & 48.09 & 100.04 & -2.76 & 73.80 \\
n-butanol & 289.95 & 44.14 & 74.12 & 4.24 & 118.75 \\
acetonitrile & 272.35 & 48.5 & 41.05 & -5.97 & 81.66 \\
2-methylpyrazine & 354.85 & 51.17 & 94.12 & 8.17 & 130.30 \\
\hline
\end{tabular}

Table 2. Flash temperatures and health hazard level of the investigated working fluids.

\begin{tabular}{cccc}
\hline Fluid & Flash Temperature $\left({ }^{\circ} \mathbf{C}\right)$ & Flammability Level & Health Hazard Level \\
\hline 2,2,2-trifluoroethanol & 29 & 3 & 2 \\
n-butanol & 35 & 3 & 1 \\
acetonitrile & 2 & 3 & 2 \\
2-methylpyrazine & 50 & 2 & 2 \\
\hline
\end{tabular}

It is well known that the behaviour of mixtures is very complex. Beyond the problems of complete mixing, the thermodynamics of the mixtures can also be anomalous as for example when retrograde condensation or the so called "isentropic inversion" occur [48,49]. Anyway, generally, these last two behaviours appear near the critical region or when one of the mixture components is supercritical, and these are not the conditions here considered.

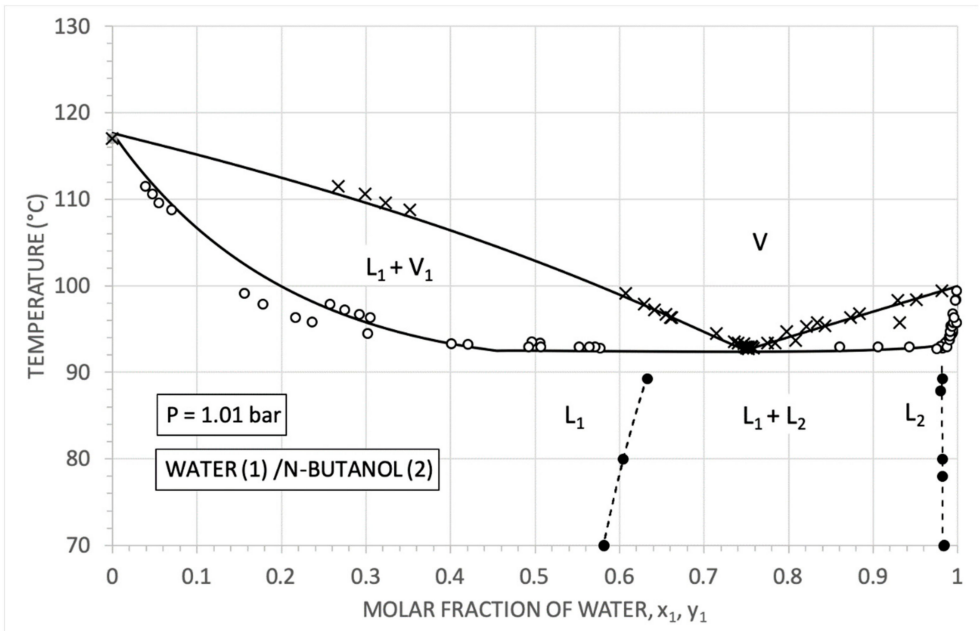

Figure 2. Isobaric VLE diagram for water/n-butanol mixture at 1 bar. Experimental values (dots and crosses, from Aspen Plus ${ }^{\circledR}$ (v 9.0)) and calculated results (solid line). Letters "V" and "L" identify vapour and liquid phases, respectively. 
The phase diagrams T-xy, in Figure 3a, Figure 4a, Figure 5a, show the behaviour of the other considered mixtures at different pressures $(0.1,1$ and 10 bar) as a function of the water content. All of the three investigated mixtures present extended near-azeotropic behaviour, in a wide range of molar compositions with limited temperature glides.

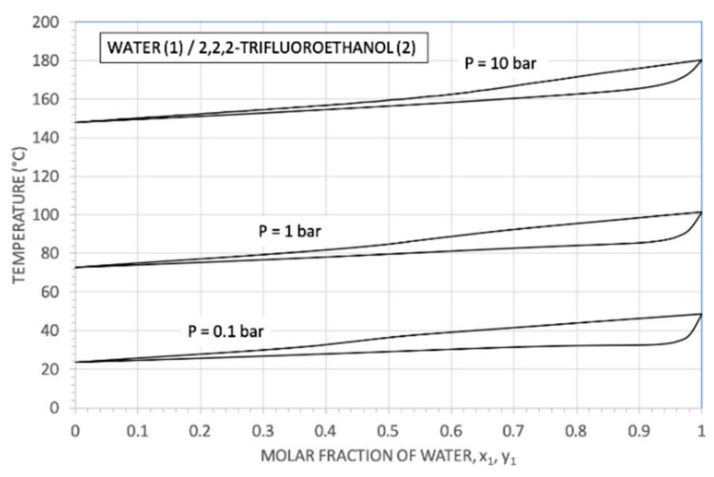

(a)

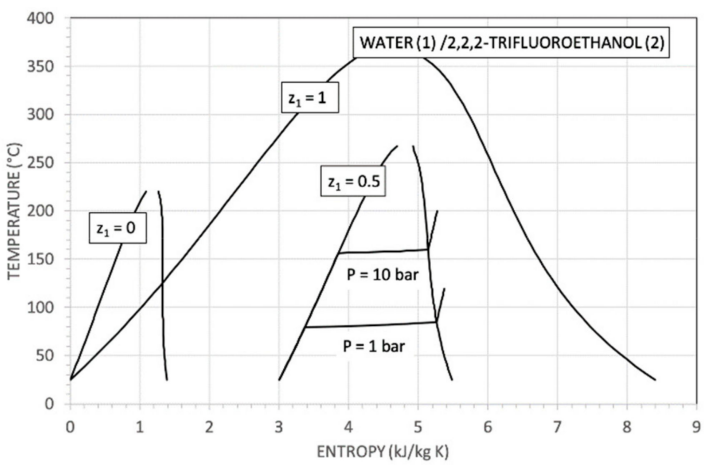

(b)

Figure 3. Water/2,2,2-trifluoroethanol mixtures: (a) phase diagram T-xy, for 0.1, 1 and 10 bar; (b) saturation curves (bubble and dew lines) in the T-S plane for mixtures at different compositions.

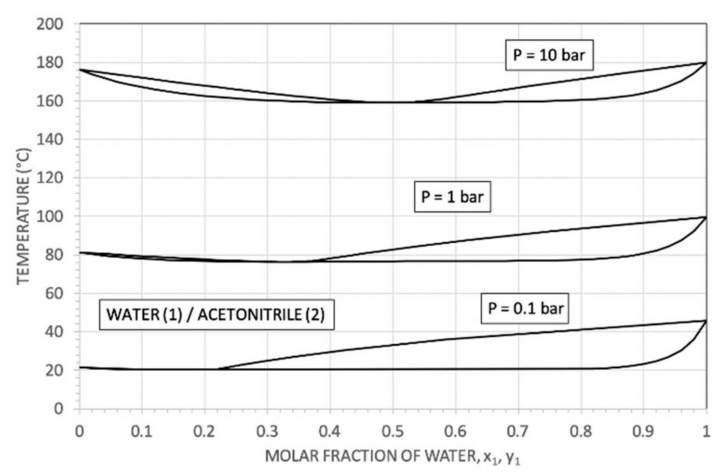

(a)

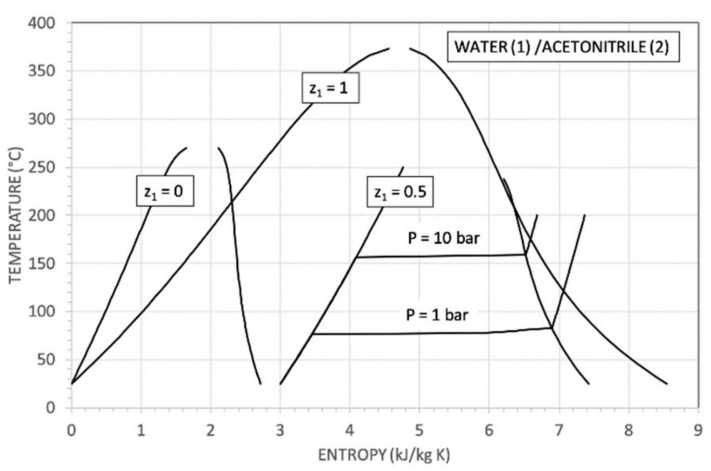

(b)

Figure 4. Water/acetonitrile mixtures: (a) phase diagram T-xy for 0.1, 1 and 10 bar; (b) saturation curves (bubble and dew lines) in T-S plane for mixtures at different composition.

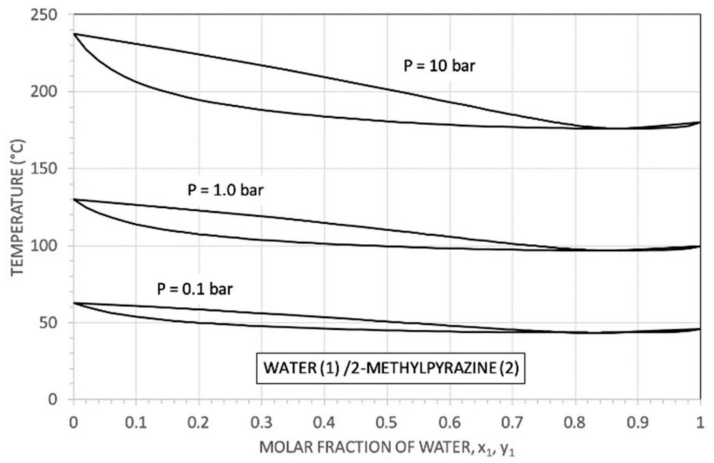

(a)

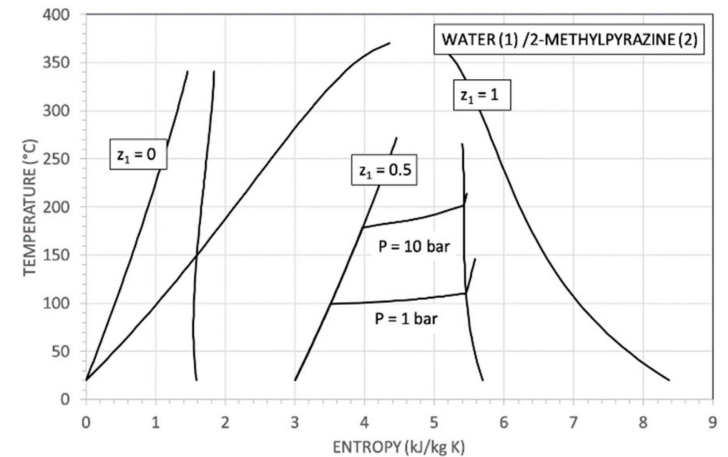

(b)

Figure 5. Water/2-methylpyrazine mixtures: (a) phase diagram T-xy for 0.1, 1 and 10 bar; (b) saturation curves (bubble and dew lines) in T-S plane for mixtures at different composition.

Figure $3 b$, Figure $4 b$, Figure $5 b$ show some saturation curves in the T-S plane where $z_{1}^{0}=1.0$ and $z_{1}^{0}=0$ correspond to pure water or pure solute respectively. Thanks to the high molecular 
complexity of 2-methylpyrazine (see Table 1), the dew line of the water mixture at $z_{1}^{0}=0.5$, in Figure $5 b$, was almost isentropic, avoiding liquid formation during fluid expansion even without superheating. This leads to no blade erosion issues due to the dry expansion [50,51]. Moreover, the medium molecular complexity with respect to siloxanes or other organic fluid $(\sigma>15-20)$ allows adopting a simple cycle configuration instead of the typical regenerative one used. A similar behaviour was seen even for the water/2,2,2-trifluoroethanol mixtures while the molecular complexity and the low molar mass of acetonitrile implied a wet expansion, as can be seen in Figure $4 \mathrm{~b}$.

Regarding the mixture flammability, the flash point is the main physical property used to determine the fire and explosion hazards of liquids: it indicates the lowest temperature at which a volatile fuel ignites or flashes when in contact with a spark or flame. The mixing with water, that is inert, can increase the flash point temperature, decreasing the flammability risk. The most commonly used flash point prediction model for aqueous-organic binary mixtures [52,53] was adopted: the author verified that the model could predict the flash points of binary and ternary aqueous mixtures by considering only the flammable component in the mixtures [54]. The flash point of 2,2,2-trifluoroethanol, for example, is $29^{\circ} \mathrm{C}$ while it increased to $59^{\circ} \mathrm{C}$ and $91^{\circ} \mathrm{C}$ for $\mathrm{z}_{1}$ equal to 0.25 and 0.5 , respectively, reducing the NFPA flammability level from F3 to F2, as shown in Figure 6.

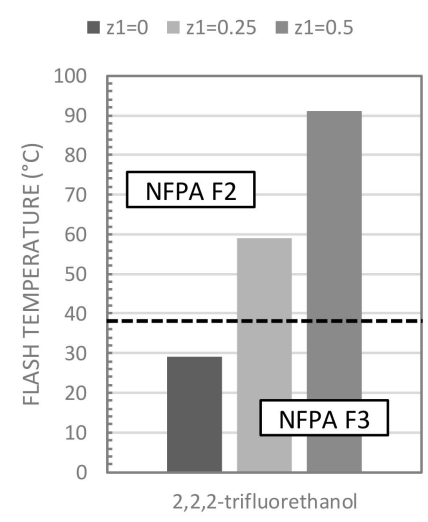

Figure 6. Water/2,2,2-trifluoroethanol mixture: flash temperature at different compositions.

\section{Organic Rankine Cycle Performance Evaluation}

\subsection{Methodology}

The thermodynamic cycle analysis started from the validation of the thermodynamic properties of the investigated water-based mixtures with VLE experimental data. All the organic Rankine cycles considered were then implemented in Aspen Plus ${ }^{\complement}$ (v 9.0) [43], where mass and energy balances were solved. Performance of saturated cycles were evaluated for different molar fractions of the investigated mixtures.

The system was designed for exploiting a non-isothermal hot water stream (i.e., geothermal source). Following the adoption of a non-isothermal heat source, the evaporation pressure became the main operating parameter to be selected.

The main design parameters and assumptions are summarized in Table 3. Three different maximum temperatures of the hot water stream were considered: 100,150 and $200{ }^{\circ} \mathrm{C}$. Pressure drops in the heat exchangers were not taken into account. All the selected mixtures results were compared in terms of maximum net power produced per unit mass flow of hot water (Equation (1)) and of turbine design.

$$
\mathrm{P}_{\text {out }}=\frac{\dot{\mathrm{m}}_{1}\left[\left[\mathrm{H}_{6}-\mathrm{H}_{8}\right]-\left[\mathrm{H}_{2}-\mathrm{H}_{1}\right]\right]}{\dot{\mathrm{m}}_{\mathrm{H}}}\left[\frac{\mathrm{kW}}{\mathrm{kg}_{\mathrm{H}} / \mathrm{s}}\right]
$$


The system layout is shown in Figure 7. The two-phase stream at the outlet of the evaporator was sent to the separator tank where the vapour stream (6) was fed to the turbine while the liquid fraction (7) was collected on the bottom section and mixed with the liquid stream (2) exiting the pump. The resulting stream (3) was pre-heated and evaporated thanks to the hot water line $(\mathrm{H})$.

Table 3. Organic Rankine cycle (ORC) system: main assumptions and parameters. (a) The "minimum temperature approach" is the minimum temperature difference between the two streams in the heat exchanger.

\begin{tabular}{ccc}
\hline Parameter & Units & Value \\
\hline T Hot water (heat source) $\left(\mathrm{T}_{\mathrm{H}, 1}\right)$ & ${ }^{\circ} \mathrm{C}$ & $100-150-200$ \\
Minimum temperature approach in the evaporator, $\mathrm{MITA}^{(\mathrm{a})} \mathrm{E}$ & ${ }^{\circ} \mathrm{C}$ & 5 \\
Vapour quality at the evaporator outlet $\left(\mathrm{x}_{4}\right)$ & $\%$ & 90 \\
$\mathrm{~T}$ air at the condenser $\left(\mathrm{T}_{\mathrm{C}, 1}\right)$ & ${ }^{\circ} \mathrm{C}$ & 15 \\
$\Delta \mathrm{T}$ air at the condenser $\left(\Delta \mathrm{T}_{\mathrm{C}}\right)$ & ${ }^{\circ} \mathrm{C}$ & 30 \\
Minimum temperature approach in the condenser, $\mathrm{MITA}^{(\mathrm{a})}{ }_{\mathrm{C}}$ & ${ }^{\circ} \mathrm{C}$ & 5 \\
Turbine isentropic efficiency $\left(\eta_{\mathrm{T}}\right)$ & $\%$ & 85 \\
Pump isentropic efficiency $\left(\eta_{\mathrm{P}}\right)$ & $\%$ & 70 \\
\hline
\end{tabular}

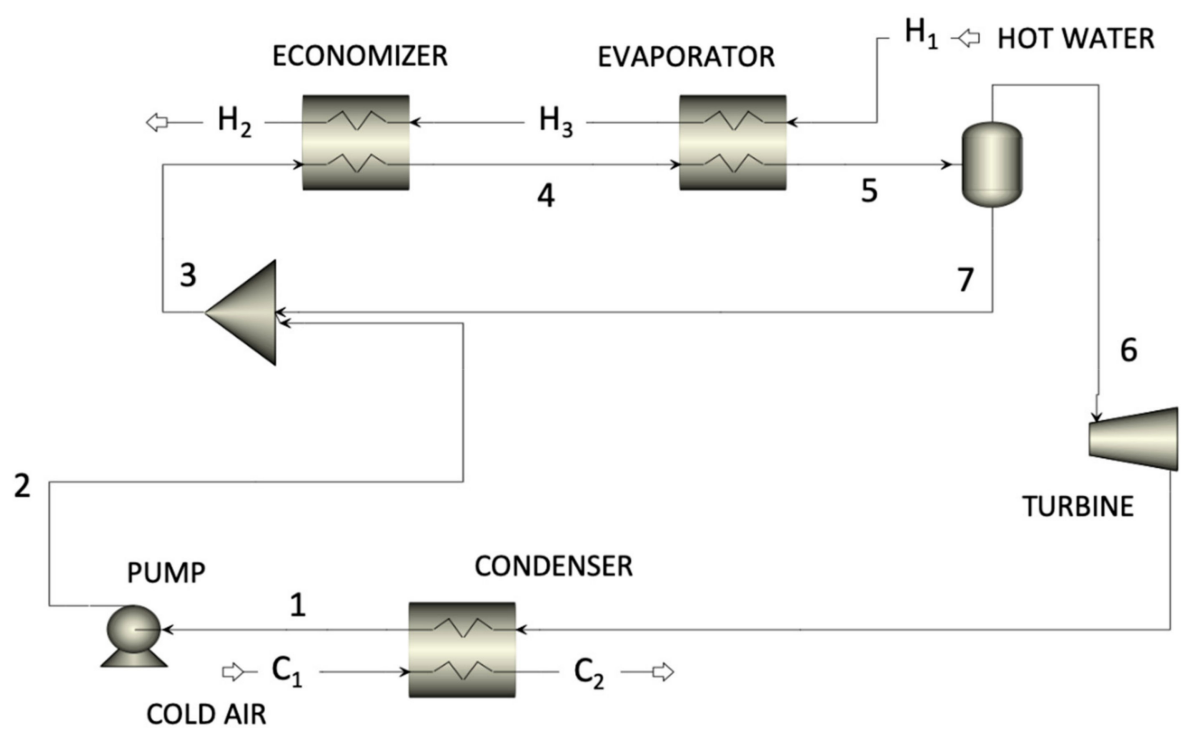

Figure 7. Organic Rankine cycle layout: Aspen Plus flowsheet.

Water mixture results were then compared with a conventional saturated steam cycle, selected as a reference case. Figure 8 shows the resulting specific net power with respect to the evaporation pressure $\left(\mathrm{P}_{\mathrm{E}}\right)$, which achieved the maximum net power per unit mass flow of hot water of 5.33, 23.04 and $53.07 \mathrm{~kW} /(\mathrm{kg} / \mathrm{s})$ with the heat source stream at 100,150 and $200^{\circ} \mathrm{C}$, respectively. The optimum evaporation pressure was between 0.34 and 2.1 bar. 


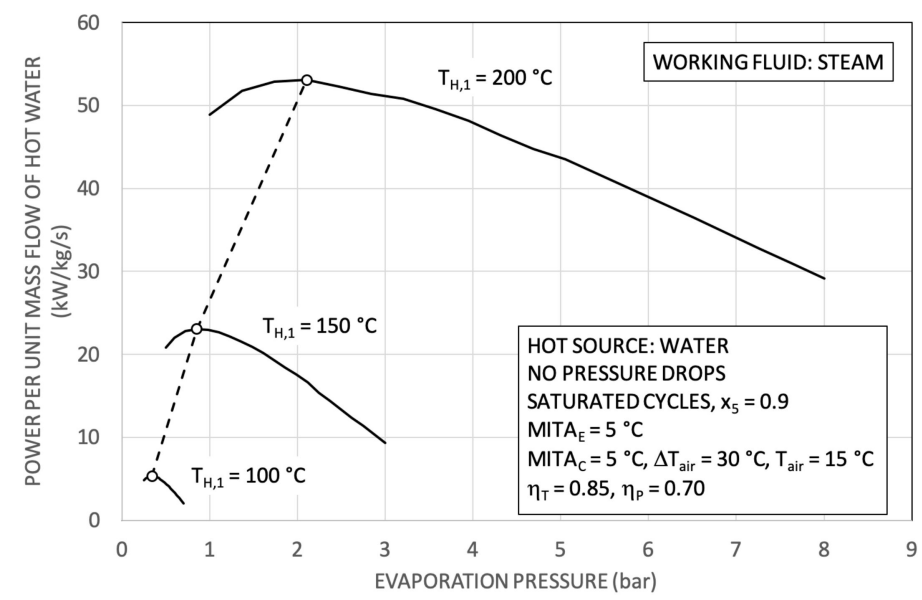

Figure 8. Thermodynamic results of the reference case with pure water.

\subsection{Results}

Thermodynamic results of the three investigated water mixtures are represented in Figure 9, where $z_{1}^{0}=1.0$ and $z_{1}^{0}=0$ correspond to pure water or pure solute respectively.

For all the mixtures and heat source levels, the net power output had a maximum for an intermediate water molar fraction, except for the water/2,2,2-trifluoroethanol mixture with the heat source at $200{ }^{\circ} \mathrm{C}$ where the presence of water slightly decreases the cycle performance.

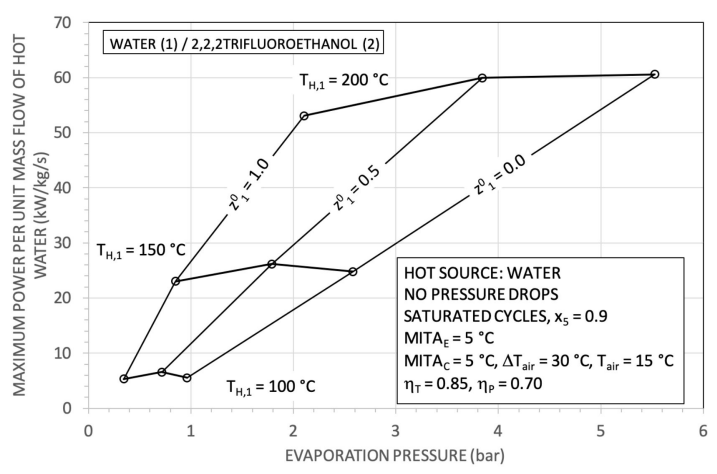

(a)

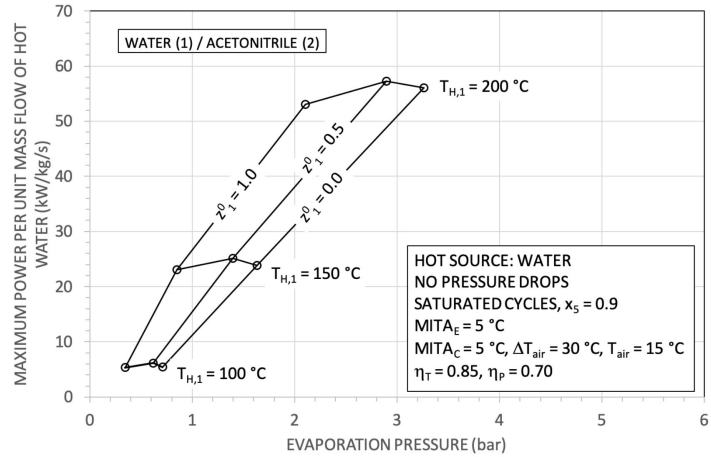

(b)

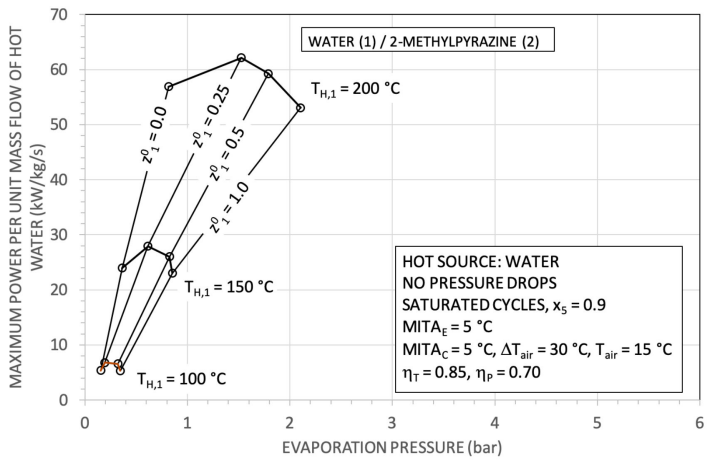

(c)

Figure 9. Net power per unit mass flow of hot water as a function of the evaporation pressure. Thermodynamic results of ORC with investigated water mixtures: (a) water/2,2,2-trifluoroethanol, (b) water/acetonitrile, (c) water/2-methylpyrazine. 
All the three pure fluids $\left(z_{1}^{0}=0\right)$ had roughly the same performance, though with different evaporation pressures. A maximum net power of about $60 \mathrm{~kW} / \mathrm{kg} / \mathrm{s}$ was obtained with pure 2,2,2-trifluoroethanol, that operated also at the highest evaporation pressure (from 1 to 5.5 bar). The pure 2-methylpyrazine worked with an evaporation pressure lower than pure water; moreover, the ORC, with this working fluid, was always at sub-atmospheric pressures. In all cases it was confirmed that water, if adopted as a pure component, would be a poor working fluid for this application.

If a mixture was adopted as the working fluid, an intermediate molar fraction of $z_{1}^{0}=0.5$ could be selected for 2,2,2-trifluoroethanol and acetonitrile while $z_{1}^{0}=0.25$ was the best water molar fraction for a water/2-methylpyrazine mixture.

Regarding the design of the turbine, the low net specific power, due to geothermal application, fits for a small turbomachinery. A one-stage ideal turbine isentropic enthalpy drop and the volume flow ratio were fixed at about $120 \mathrm{~kJ} / \mathrm{kg}$ and $1.5-2$ respectively, assuming a reaction degree $(\Lambda)$ of 0.5 and a maximum allowed peripheral speed $u_{\max }$ of $350 \mathrm{~m} / \mathrm{s}$.

The adoption of water mixtures as working fluids reduced the specific turbine isentropic enthalpy drop with respect to pure water, which kept a similar volume flow ratio, as shown in Figure 10. In the case of $\mathrm{T}_{\mathrm{H}, 1}=150^{\circ} \mathrm{C}$, the turbine could be limited to one stage, despite the water mixture with 2,2,2-trifluoroethanol and 2-methylpyrazine showed a volume flow ratio higher than 6 . As stated in Reference [4], a maximum value of 10 can be accepted for one stage. For a heat source with a temperature higher than $150^{\circ} \mathrm{C}$, at least two stages were required with peripheral speeds drastically lower compared to pure water, since the speed is a function to the isentropic enthalpy drop (see comparison between Figure 10a,b). Also, the size parameter (SP) should be taken into account for a proper turbine design. For example, assuming an isentropic turbine power equal to $1 \mathrm{MW}$ at $\mathrm{T}_{\mathrm{H}, 1}=150{ }^{\circ} \mathrm{C}$ that had a $\mathrm{SP}$ in the range of $0.2-0.6$ for all the fluids, the resulting volume flow rate for pure water was about 2 times higher compared to the water mixture with 2,2,2-trifluoroethanol and acetonitrile.

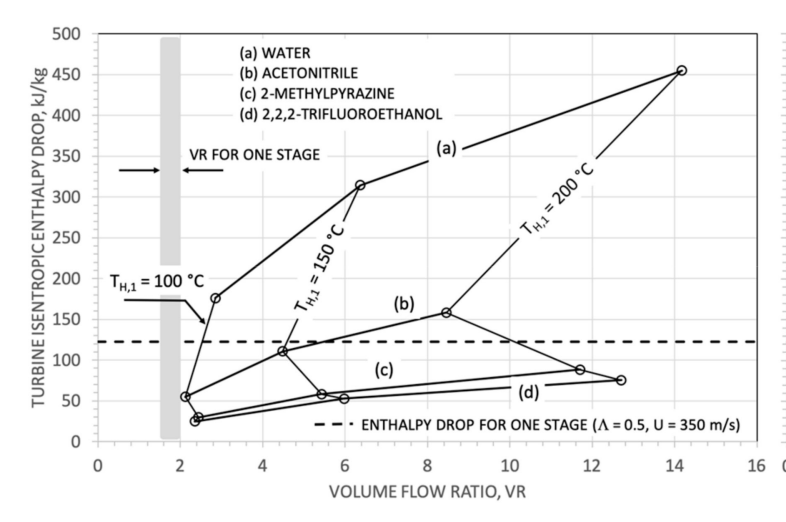

(a)

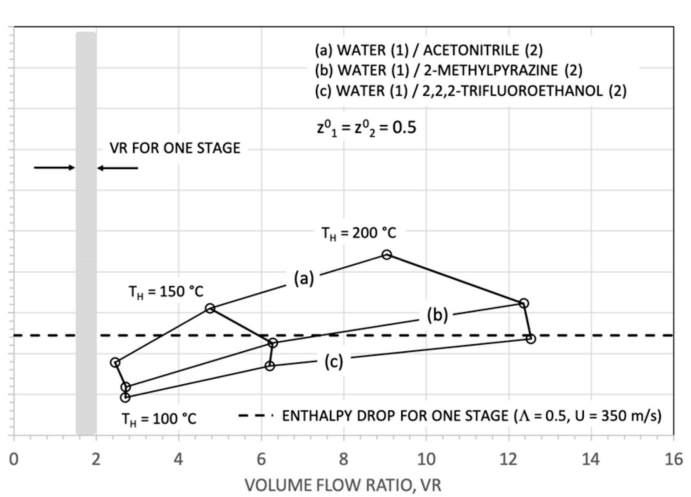

(b)

Figure 10. Turbine isentropic enthalpy drop and volume flow ratio for heat sources at different temperatures: (a) pure fluids and (b) investigated mixtures.

Finally, the use of water-mixtures added two variables to the cycle optimization. The choice of both the solute and of the mixture composition allowed the size of the turbine to be tailored with respect to the ORC size (or the produced electric power). Starting from (i) a one-stage turbine, (ii) a size parameter of 0.5 , (iii) a heat source at $150^{\circ} \mathrm{C}$ and (iv) a mixture where the two components had the same molar fraction (0.5/0.5), the water/2,2,2-trifluoroethanol lead to $4 \mathrm{MW}$ while the water/2-methylpyrazine mixture had half of the power (2 MW). On the other hand, the pure fluid 2-methylpyrazine could not go over $0.7 \mathrm{MW}$.

The potential benefits of the water-mixtures are (i) the design of small turbomachinery at fixed ORC size with respect to pure water and (ii) the reduction of the flammability of the working fluid, with respect the adoption of pure fluids. 


\section{Thermal Stability}

Preliminary experimental tests for the thermal stability of alcohol class compounds (2,2,2-trifluoroethanol and n-butanol) were conducted in order to check their applicability range. The analysis may be extended in future works to the other solutes and to different water mixtures. As the selected fluids may be suitable as pure working fluids in an ORC system with different heat sources, the thermal stability tests were carried out at even higher temperatures with respect to the geothermal source of this work.

The thermal stability test method, as discussed in [55-57], compare the vapour pressure of the fluid before and after the thermal stress test. The test circuit, in stainless steel AISI 316, consists of a sample cylinder, one thermocouple (type $\mathrm{K}$ ), two pressure transmitters that cover a wide range of pressure from 1 to 100 bar and some block valves to charge and isolate the investigated fluid. More details on the experimental apparatus are discussed in $[13,55]$. The vapour pressure deviations, or the fluid decomposition, from the virgin fluid behaviour were evaluated both at high temperatures, during the thermal stress tests, and at temperature close to ambient conditions. After the preparation of the fluid sample, the experimental procedure consisted of a thermal stress in an electric oven at high temperatures for a typical time span of $80 \mathrm{~h}$, followed by the measure of the vapour pressure profile of the investigated fluid. Experimental test conditions of the fluids are summarized in Table 4. As shown in Figures 11 and 12, results were compared with the values of the $\mathrm{p}-\mathrm{T}$ curve obtained for the fluid sample before the series of thermal stress tests for the three fluids. The measured values of the vapour pressure $\mathrm{P}_{\mathrm{v}}$ for the virgin fluid were fitted by Equation (2), whose coefficients $\mathrm{A}$ and $\mathrm{B}$ are reported respectively in Figures 11a and 12a.

$$
\ln \mathrm{P}_{\mathrm{v}}=\mathrm{A}+\frac{\mathrm{B}}{\mathrm{T}}
$$

Table 4. Thermal stress tests conditions.

\begin{tabular}{ccccc}
\hline Fluid & Fluid Charge $(\mathrm{g})$ & $\mathbf{T}\left({ }^{\circ} \mathbf{C}\right)$ & $\Delta \mathrm{T}_{\text {step }}\left({ }^{\circ} \mathbf{C}\right)$ & Time $_{\text {step }}(\mathbf{h})$ \\
\hline 2,2,2-trifluoroethanol & 35 & $200-320$ & 10 & 80 \\
n-butanol & 26 & $160-280$ & 20 & $\left(60\right.$ at $\left.310{ }^{\circ} \mathrm{C}\right)$ \\
\hline
\end{tabular}




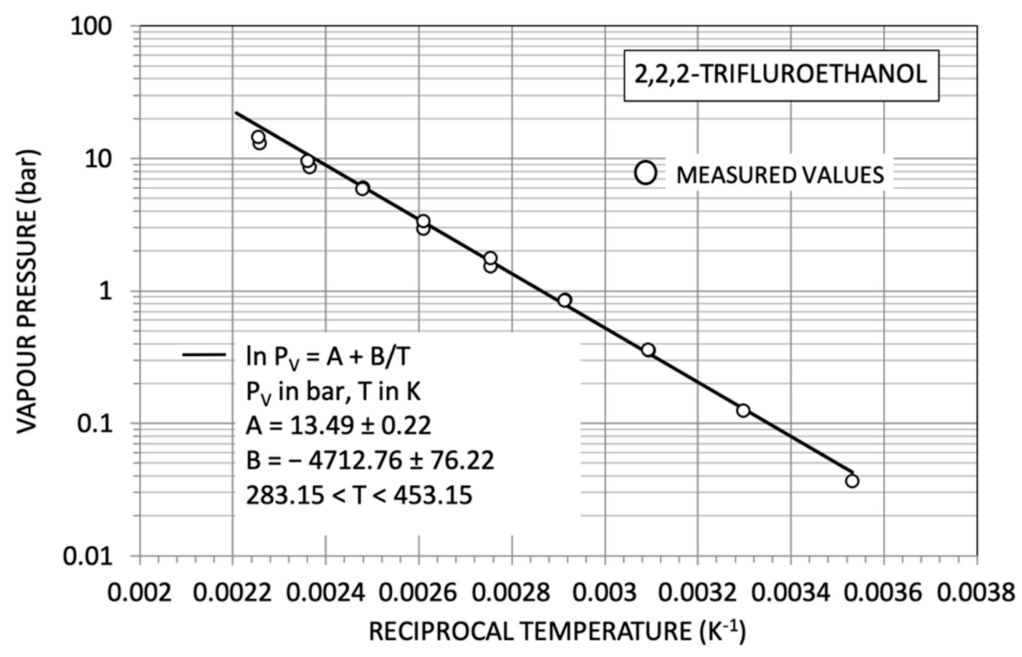

(a)

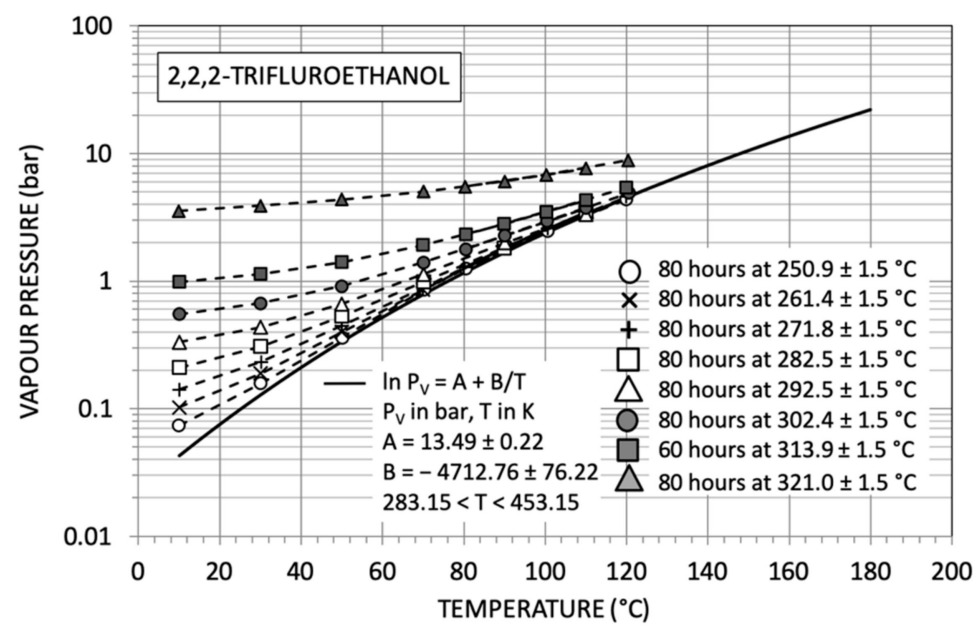

(b)

Figure 11. Thermal stability test for 2,2,2-trifluoroethanol: (a) reference vapour pressure (virgin fluid), (b) vapour pressure profile after different thermal stress temperatures. 


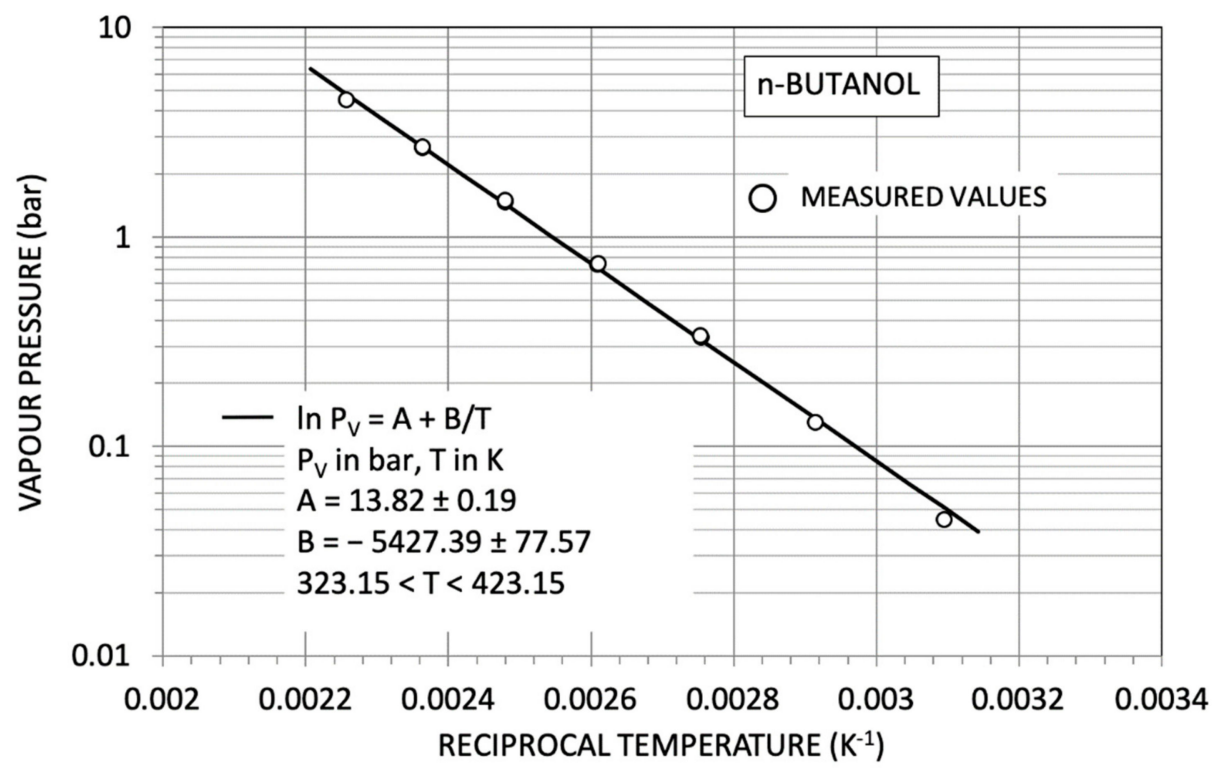

(a)

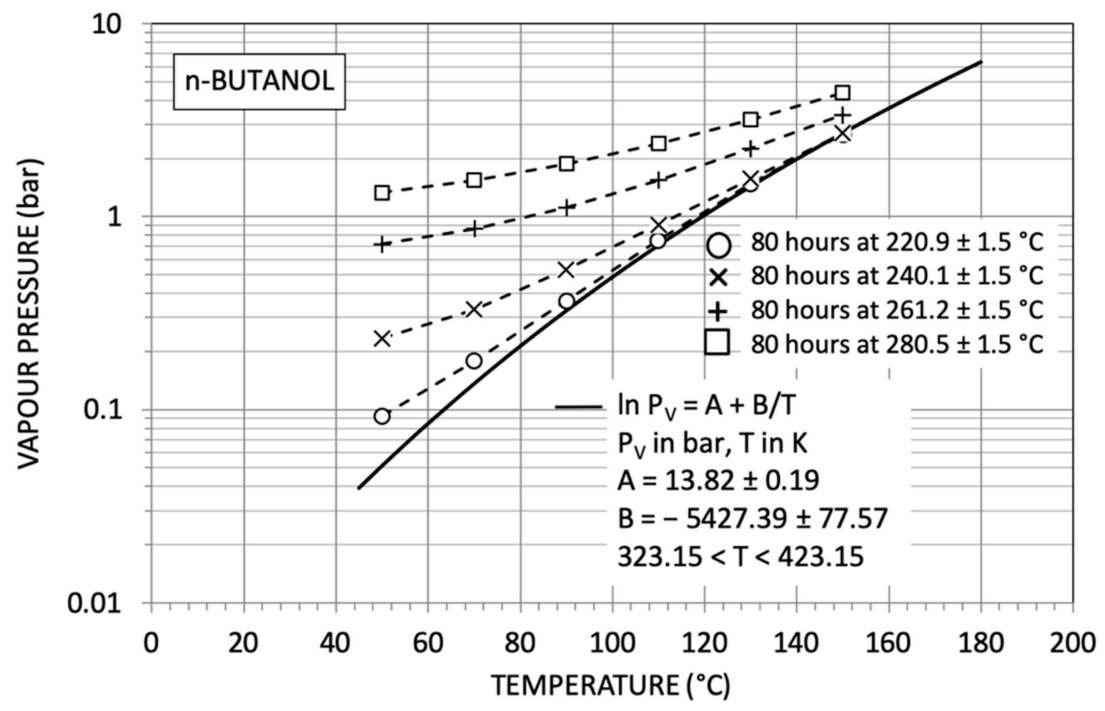

(b)

Figure 12. Thermal stability test for $n$-butanol: (a) reference vapour pressure (virgin fluid), (b) vapour pressure profile after different thermal stress temperatures.

Figure 13 reports the quasi-constant of the velocity reaction $k^{*}$, which is a parameter correlated to the number of decomposed moles [56], as a function of the reciprocal of the stress temperature for the fluids 2,2,2-trifluoroethanol and n-butanol. For a fixed decomposition rate $k^{*}=1 \cdot 10^{-9} s^{-1}$, the corresponding temperatures are about $300{ }^{\circ} \mathrm{C}$ and $250{ }^{\circ} \mathrm{C}$ for the first and the second fluid respectively. Just for a comparison, toluene (a well known thermally stable organic fluid) reaches the same value of $k^{*}$ at a temperature of about $400{ }^{\circ} \mathrm{C},[56,58]$. From the temperature point of view, the value of the parameter $k^{*}$ at $300{ }^{\circ} \mathrm{C}$ for the n-butanol was about ten times respect to the 2,2,2-trifluoroethanol: in fact, the fluorine content is well-known to make the latter more stable. 


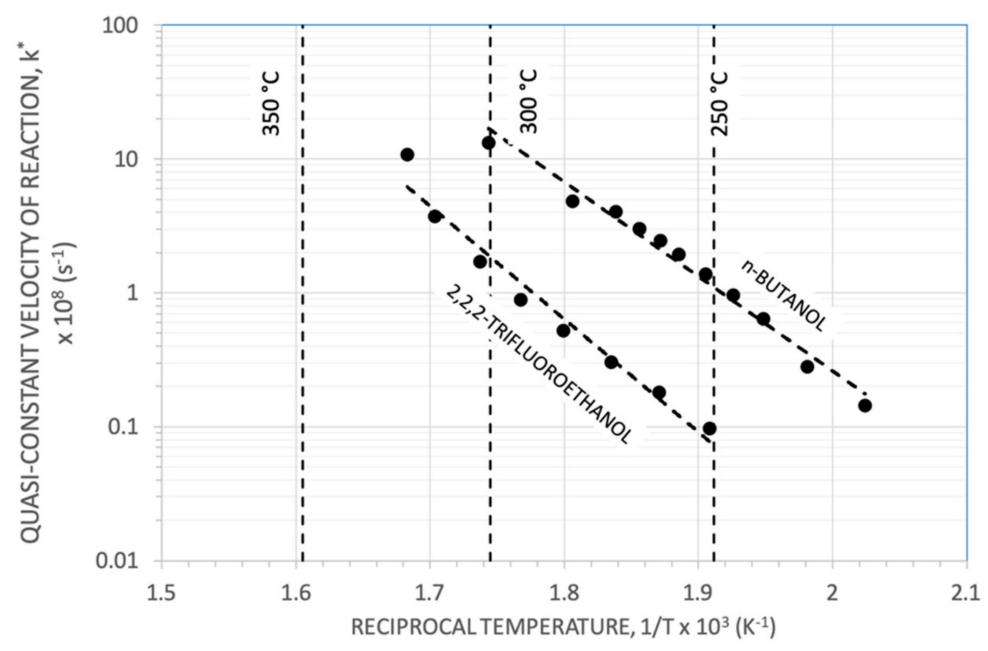

Figure 13. Quasi-constant of the velocity reaction $k^{*}$ as a function of the reciprocal of the stress temperature for n-butanol, and 2,2,2-trifluoroethanol.

\section{Conclusions}

The work showed that the adoption of water-based mixture as a working fluid in ORCs, is convenient in terms of system performance, turbine design and safety concerns for the investigated heat source temperature range $\left(100-200{ }^{\circ} \mathrm{C}\right)$ for two reasons:

1) mixture of organic fluids with water can drastically extend the working fluid selection with potential advantages in terms of safety concerns, thus reducing the flammability and toxicity;

2) thermodynamic properties can be tailored case-by-case to the heat source power and temperature level.

Among the investigated mixtures, the 2,2,2-trifluoroethanol mixture appeared as the most promising one: it allowed an effective exploitation of the heat source, which resulted in an adequate plant performance, and allowed a convenient sizing of the turbine. Moreover, thermal stability tests confirmed that 2,2,2-trifluoroethanol could work at the investigated operating temperature range with negligible thermal decomposition.

As there are many substances that can be mixed with water, we think the topic deserves further study. However, the problem does not seem of simple resolution, particularly if azeotropic mixtures and compositions need to be identified. In addition to toxicity, flammability and acceptable environmental performance, as a matter of fact, a substantial improvement of the thermodynamic properties of pure water requires solutes with high molar mass, high molecular complexity and completely solubility in water: after this preliminary investigation, this does not seem easy.

Author Contributions: Conceptualization, C.I.; Methodology, M.B., P.B., G.D.M., C.I., P.I., G.M.; Software, C.I..; Investigation, M.B., P.B., G.D.M., C.I., P.I., G.M.; Writing—original draft preparation, M.B., P.B., G.D.M., C.I., P.I., G.M.; Supervision, C.I.

Funding: This research was funded by the University of Brescia under the Health and Wealth Project "Brescia 20-20-20".

Acknowledgments: The authors thank Modestino Savoia for his effort and contribution to the laboratory activities.

Conflicts of Interest: The authors declare no conflict of interest.

\section{Nomenclature}

$\begin{array}{ll}\text { A } & \text { Coefficient of vapour pressure equation, bar } \\ \text { B } & \text { Coefficient of vapour pressure equation, bar K } \\ \mathrm{H} & \text { Specific enthalpy, } \mathrm{kJ} / \mathrm{kg} \\ \mathrm{k}^{*} & \text { Quasi-constant velocity of reaction, } \mathrm{s}^{-1} \\ \text { MITA } & \text { Minimum temperature approach, }{ }^{\circ} \mathrm{C}\end{array}$




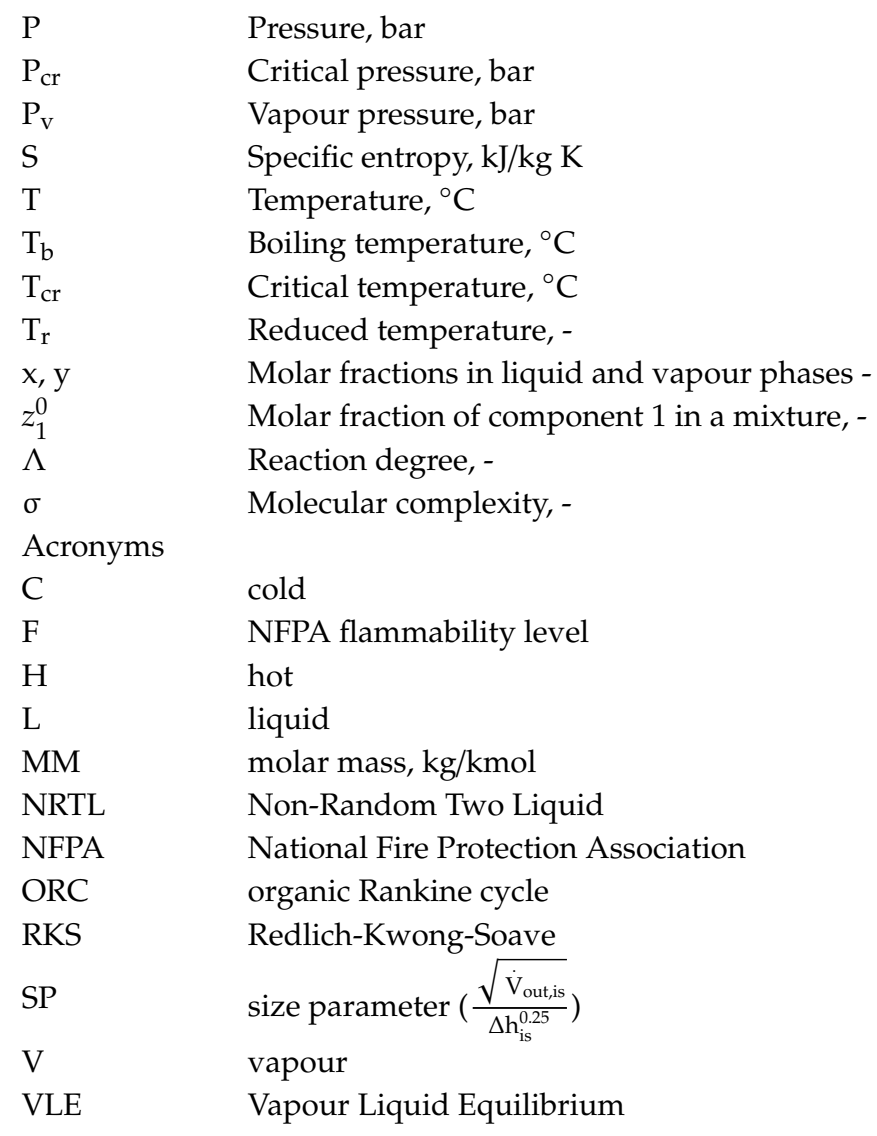

\section{References}

1. Invernizzi, C.M.; Iora, P.; Preißinger, M.; Manzolini, G. HFOs as substitute for R-134a as working fluids in ORC power plants: A thermodynamic assessment and thermal stability analysis. Appl. Therm. Eng. 2016, 103, 790-797. [CrossRef]

2. Dai, X.; Shi, L.; An, Q.; Qian, W. Screening of working fluids and metal materials for high temperature organic Rankine cycles by compatibility. J. Renew. Sustain. Energy 2017, 9. [CrossRef]

3. Tchanche, B.F.; Papadakis, G.; Lambrinos, G.; Frangoudakis, A. Fluid selection for a low-temperature solar organic Rankine cycle. Appl. Therm. Eng. 2009, 29, 2468-2476. [CrossRef]

4. Macchi, E.; Astolfi, M. Organic Rankine Cycle (ORC) Power Systems: Technologies and Applications. Woodhead Publishing Elsevier: Amsterdam, The Netherlands, 2016.

5. Astolfi, M.; Lasala, S.; Macchi, E. Selection Maps for ORC and $\mathrm{CO}_{2}$ Systems for Low-Medium Temperature Heat Sources. Energy Procedia 2017, 129, 971-978. [CrossRef]

6. Sprouse, C.; Depcik, C. Review of organic Rankine cycles for internal combustion engine exhaust waste heat recovery. Appl. Therm. Eng. 2013, 51,711-722. [CrossRef]

7. Linke, P.; Papadopoulos, I.A.; Seferlis, P. Systematic Methods for Working Fluid Selection and the Design, Integration and Control of Organic Rankine Cycles-A Review. Energies 2015, 8, 4755-4801. [CrossRef]

8. Blondel, Q.; Tauveron, N.; Caney, N.; Voeltzel, N. Experimental Study and Optimization of the Organic Rankine Cycle with Pure NovecTM649 and Zeotropic Mixture NovecTM649/HFE7000 as Working Fluid. Appl. Sci. 2019, 9, 1865. [CrossRef]

9. Invernizzi, C.; Sheikh, N. High-efficiency small-scale combined heat and power organic binary Rankine cycles. Energies 2018, 11, 994. [CrossRef]

10. Le, V.L.; Feidt, M.; Kheiri, A.; Pelloux-Prayer, S. Performance optimization of low-temperature power generation by supercritical ORCs (organic Rankine cycles) using low GWP (global warming potential) working fluids. Energy 2014, 67, 513-526. [CrossRef] 
11. Moloney, F.; Almatrafi, E.; Goswami, D.Y. Working fluid parametric analysis for regenerative supercritical organic Rankine cycles for medium geothermal reservoir temperatures. Energy Procedia 2017, 129, 599-606. [CrossRef]

12. Scaccabarozzi, R.; Tavano, M.; Invernizzi, C.M.; Martelli, E. Comparison of working fluids and cycle optimization for heat recovery ORCs from large internal combustion engines. Energy 2018, 158, 396-416. [CrossRef]

13. Keulen, L.; Gallarini, S.; Landolina, C.; Spinelli, A.; Iora, P.; Invernizzi, C.; Lietti, L.; Guardone, A. Thermal stability of hexamethyldisiloxane and octamethyltrisiloxane. Energy 2018, 165, 868-876. [CrossRef]

14. Luo, X.; Liang, Z.; Guo, G.; Wang, C.; Chen, Y.; Ponce-Ortega, J.M.; El-Halwagi, M.M. Thermo-economic analysis and optimization of a zoetropic fluid organic Rankine cycle with liquid-vapor separation during condensation. Energy Convers. Manag. 2017, 148, 517-532. [CrossRef]

15. Oyewunmi, O.A.; Kirmse, C.J.W.; Pantaleo, A.M.; Markides, C.N. Performance of working-fluid mixtures in ORC-CHP systems for different heat-demand segments and heat-recovery temperature levels. Energy Convers. Manag. 2017, 148, 1508-1524. [CrossRef]

16. Di Battista, D.; Cipollone, R.; Villante, C.; Fornari, C.; Mauriello, M. The Potential of Mixtures of Pure Fluids in ORC-Based Power Units Fed by Exhaust Gases in Internal Combustion Engines. Energy Procedia 2016, 101, 1264-1271. [CrossRef]

17. Andreasen, J.G.; Larsen, U.; Knudsen, T.; Pierobon, L.; Haglind, F. Selection and optimization of pure and mixed working fluids for low grade heat utilization using organic rankine cycles. Energy 2014, 73, 204-213. [CrossRef]

18. Abadi, G.B.; Kim, K.C. Investigation of organic Rankine cycles with zeotropic mixtures as a working fluid: Advantages and issues. Renew. Sustain. Energy Rev. 2017, 73, 1000-1013. [CrossRef]

19. Xu, W.; Deng, S.; Zhang, Y.; Zhao, D.; Zhao, L. How to give a full play to the advantages of zeotropic working fluids in organic Rankine cycle (ORC). Energy Procedia 2019, 158, 1591-1597. [CrossRef]

20. Miao, Z.; Zhang, K.; Wang, M.; Xu, J. Thermodynamic selection criteria of zeotropic mixtures for subcritical organic Rankine cycle. Energy 2019, 167, 484-497. [CrossRef]

21. Dong, B.; Xu, G.; Li, T.; Quan, Y.; Wen, J. Thermodynamic and economic analysis of zeotropic mixtures as working fluids in low temperature organic Rankine cycles. Appl. Therm. Eng. 2018, 132, 545-553. [CrossRef]

22. Zhai, H.; An, Q.; Shi, L. Zeotropic mixture active design method for organic Rankine cycle. Appl. Therm. Eng. 2018, 129, 1171-1180. [CrossRef]

23. Micheli, D.; Pinamonti, P.; Reini, M.; Taccani, R. Performance Analysis and Working Fluid Optimization of a Cogenerative Organic Rankine Cycle Plant. J. Energy Resour. Technol. 2013, 135, 21601-21611. [CrossRef]

24. De Marchi Desenzani, P.; Gaia, M.; Invernizzi, C. Modification of working fluid in geothermal organic Rankine cycle engines. Int. Symp. Geotherm. Energy, Geotherm. Resour. Counc. 1985. Available online: https://www.geothermal-library.org/index.php?mode=pubs\&action=view\&record=1001478 (accessed on 6 July 2019).

25. Collings, P.; Yu, Z.; Wang, E. A dynamic organic Rankine cycle using a zeotropic mixture as the working fluid with composition tuning to match changing ambient conditions. Appl. Energy 2016, 171, 581-591. [CrossRef]

26. Liu, C.; Gao, T. Off-design performance analysis of basic ORC, ORC using zeotropic mixtures and composition-adjustable ORC under optimal control strategy. Energy 2019, 171, 95-108. [CrossRef]

27. Siemens. Siemens Technical Papers on Steam Turbines. 2019. Available online: www.energy.siemens.com/ hq/en/energy-topics/publications/technical-papers/steam-turbines.htm (accessed on 11 May 2019 ).

28. Rogdakis, E.D. Thermodynamic analysis, parametric study and optimum operation of the Kalina cycle. Int. J. Energy Res. 1996, 20, 359-370. [CrossRef]

29. Somekh, G.S. Water-Pyridine Azeotrope is an Excellent Rankine Cycle Fluid. J. Eng. Power 1975, 97, 583-588. [CrossRef]

30. Patel, P.; Doyle, E.F.; Raymond, R.J.; Sakhuia, R. Automotive Organic Rankine-Cycle Powerplant-Design and Performance Data; SAE Paper; SAE: Detroit, MI, USA, No. 740297.

31. Victor, R.A.; Kim, J.-K.; Smith, R. Composition optimisation of working fluids for Organic Rankine Cycles and Kalina cycles. Energy 2013, 55, 114-126. [CrossRef]

32. Ibrahim, O.M.; Klein, S.A. Absorption power cycles. Energy 1996, 21, 21-27. [CrossRef]

33. Heberle, F.; Preißinger, M.; Brüggemann, D. Zeotropic mixtures as working fluids in Organic Rankine Cycles for low-enthalpy geothermal resources. Renew. Energy 2012, 37, 364-370. [CrossRef] 
34. Baik, Y.-J.; Kim, M.; Chang, K.-C.; Lee, Y.-S.; Yoon, H.-K. Power enhancement potential of a mixture transcritical cycle for a low-temperature geothermal power generation. Energy 2012, 47, 70-76. [CrossRef]

35. Eller, T.; Heberle, F.; Brüggemann, D. Second law analysis of novel working fluid pairs for waste heat recovery by the Kalina cycle. Energy 2017, 119, 188-198. [CrossRef]

36. Miller, D.R.; Null, H.R.; Thompson, Q.E. Optimum Working Fluids for Automotive Rankine Engines—Volume II; US Environmental Protection Agency: Washington, DC, USA, 1973.

37. Teng, H.; Regner, G.; Cowland, C. Waste Heat Recovery of Heavy-Duty Diesel Engines by Organic Rankine Cycle Part I: Hybrid Energy System of Diesel and Rankine Engines; SAE Technical Paper; SAE: Detroit, MI, USA, No. 2007-01-0537; 2007.

38. Teng, H.; Regner, G.; Cowland, C. Waste Heat Recovery of Heavy-Duty Diesel Engines by Organic Rankine Cycle Part II: Working Fluids for WHR-ORC; SAE Technical Paper; SAE: Detroit, MI, USA, 2007; No. 2007-01-0543.

39. Katta, K.K.; Kim, M.; Taggett, M. Exhaust Heat Co-Generation System Using Phase Change Cooling for Heavy Duty Vehicles; SAE Technical Paper; SAE: Detroit, MI, USA, 2008; No. 2008-01-2450.

40. Jain, M.L.; Demirgian, J.C.; Cole, R.L. Organic Rankine-Cycle Power Systems—Working Fluids Study: Topical Report No. 1-Fluorinol 85; Argonne National Laboratory: Lemont, IL, USA, 1986.

41. Verneau, A.; Sulle, C. Recovery from exhaust gas on a diesel engine. In Proceedings of the 16th International Congress on Combustion Engines (CIMAC), Oslo, Norway, 3-7 June 1985.

42. Absalam-Gadzhievich, D.T.; Ramazanovich, B.A. Research of Thermal Stability of Water Mixtures of Aliphatic Alcohols. J. Mater. Sci. Eng. A 2012, 2, 786-790.

43. AspenTech, Aspen Plus. Available online: http://www.aspentech.com/products/aspen-plus.aspx (accessed on 11 May 2019).

44. Renon, H.; Prausnitz, J.M. Local compositions in thermodynamic excess functions for liquid mixtures. AIChE J. 1968, 14, 135-144. [CrossRef]

45. Sandler, S.I. Chemical, Biochemical, and Engineering Thermodynamics, 5th ed.; John Wiley \& Sons: Hoboken, NJ, USA, 2017.

46. Invernizzi, C.; Iora, P.; Silva, P. Bottoming micro-Rankine cycles for micro-gas turbines. Appl. Therm. Eng. 2007, 27, 100-110. [CrossRef]

47. U.S.-Based National Fire Protection Association, NFPA 704-Standard System for the Identification of the Hazards of Materials for Emergency Response. 2017. Available online: https://www.nfpa.org/codes-andstandards/all-codes-and-standards/list-of-codes-and-standards/detail?code=704 (accessed on 11 May 2019).

48. Deiters, U.K.; Kraska, T. High-Pressure Fluid Phase Equilibria: Phenomenology and Computation. 2012. Available online: https://books.google.ru/books?hl=ru\&lr=\&id=28INNEzVnWsC\&oi=fnd\& pg=PP1\&dq=Deiters+U.K., +Kraska+Th. + High-Pressure+Fluid+Phase+Equilibria:+Phenomenology+ and+Computation.+2012+Elsevier+B.V.,+Oxford, +Amsterdam.\&ots=o0u6dVpxLG\&sig=GvC4cfCQVeNWYX211Dg_snso7k\&re (accessed on 11 May 2019).

49. Imre, A.R.; Quiñones-Cisneros, S.E.; Deiters, U.K. Adiabatic Processes in the Vapor-Liquid Two-Phase Region. 2. Binary Mixtures. Ind. Eng. Chem. Res. 2015, 54, 6559-6568. [CrossRef]

50. Hesketh, J.A.; Walker, P.J. Effects of Wetness in Steam Turbines. Proc. Inst. Mech. Eng. Part C J. Mech. Eng. Sci. 2005, 219, 1301-1314. [CrossRef]

51. Petr, V.; Kolovratnik, M. Wet steam energy loss and related Baumann rule in low pressure steam turbines. Proc. Inst. Mech. Eng. Part A J. Power Energy 2013, 228, 206-215. [CrossRef]

52. Liaw, H.J.; Chiu, Y.Y. The prediction of the flash point for binary aqueous-organic solutions. J. Hazard. Mater. 2003, 101, 83-106. [CrossRef]

53. Jadot, R.; Fraiha, M. Isobaric vapor-liquid equilibrium of 2,2,2-Trifluoroethanol with water and 1-Propanol binary systems. J. Chem. Eng. Data 1988, 33, 237-240. [CrossRef]

54. Phoon, L.Y.; Mustaffa, A.A.; Hashim, H.; Mat, R. A review of flash point prediction models for flammable liquid mixtures. Ind. Eng. Chem. Res. 2014, 53, 12553-12565. [CrossRef]

55. Pasetti, M.; Invernizzi, C.M.; Iora, P. Thermal stability of working fluids for organic Rankine cycles: An improved survey method and experimental results for cyclopentane, isopentane and $n$-butane. Appl. Therm. Eng. 2014, 73, 762-772. [CrossRef]

56. Invernizzi, C.M.; Iora, P.; Manzolini, G.; Lasala, S. Thermal stability of $n$-pentane, cyclo-pentane and toluene as working fluids in organic Rankine engines. Appl. Therm. Eng. 2017, 121, 172-179. [CrossRef] 
57. Invernizzi, C.M.; Iora, P.; Bonalumi, D.; Macchi, E.; Roberto, R.; Caldera, M. Titanium tetrachloride as novel working fluid for high temperature Rankine Cycles: Thermodynamic analysis and experimental assessment of the thermal stability. Appl. Therm. Eng. 2016, 107, 21-27. [CrossRef]

58. Havens, V.N.; Ragaller, D.R.; Sibert, L.; Miller, D. Toluene stability space station Rankine power system. In Proceedings of the 22nd Intersociety Energy Conversion Engineering Conference, Philadelphia, PA, USA, 10-14 August 1987; pp. 121-126.

(C) 2019 by the authors. Licensee MDPI, Basel, Switzerland. This article is an open access article distributed under the terms and conditions of the Creative Commons Attribution (CC BY) license (http://creativecommons.org/licenses/by/4.0/). 